\title{
Automation of the process of applying plaster on the walls of agricultural premises
}

\author{
Olga Tsvetkova ${ }^{1, *}$, Andrey Aidinyan ${ }^{1}$, and Elena Chujkova ${ }^{1}$ \\ ${ }^{1}$ Don State Technical University, 1, Gagarina Sq., 344003, Rostov-on-Don, Russia
}

\begin{abstract}
Plastering works are distinguished by complex technology and the use of a large number of manual working methods. Eliminate manual labor, significantly increase productivity and improve the quality of the plastering is possible based on the automation of applying plaster. The article discusses two ways to control the amount of plaster mixture: direct regulation of the amount of plaster mixture by changing the performance of the nozzle and regulation of the amount of plaster mixture by optimizing the speed of the nozzle. The disadvantage of the first method is the need for preliminary calculation of the time instant of the nozzle productivity change. The difficulty in solving this problem is due to the inertia of the device. In connection with these difficulties, it is proposed to use the second method of adjusting the amount of plaster mixture by optimizing the speed of the nozzle. The simulation of the proposed control system was carried out in the Matlab Simulink. The developed technique for applying plaster during automatic adjustment of the nozzle speed provides the necessary speed of the working tool depending on the surface irregularities.
\end{abstract}

\section{Introduction plastering works}

In most industries, robots and mechatronic complexes are used to increase labor productivity, work efficiency, and product quality. However, in the field of construction, robotization is not widespread. The introduction of robots at construction sites is complicated by the unpredictability of the environment and the presence of a large number of people.

To reduce the duration of construction, reduce the risk of injury to workers and perform construction work in extremely harsh conditions, many researchers are considering the idea of introducing autonomous robots for construction work [1,2]. The use of robots in construction will reduce the number of time-consuming operations and construction time; will provide the opportunity to obtain complex geometric shapes that require significant labor and time costs [3]. Construction companies introducing robots into the technological process will be able to get a great advantage over competitors, increasing their efficiency using all kinds of specialized robots, robotic manipulators and drones. Robots can be equipped with various attachments, which in combination with high maneuverability makes them more efficient than traditional technologies, both in terms of speed of work and in

*Corresponding author: olga_cvetkova@mail.ru 
terms of economic feasibility. The small size and weight characteristics of such equipment make it convenient to transport. Traditional construction methods produce an excessive amount of construction waste, which is not only harmful to the environment, but also significantly affects profitability. Robotic process automation can help reduce the amount of waste generated, thanks to its ability to provide precision and accuracy.

Currently, robots are effectively used for laying bricks, lifting and installing large glass panels, sandwich panels, metal sheets and other building elements that have considerable value and dimensions $[4,5]$. Such devices are used where it is inconvenient to use traditional cranes or hoists.

Robots are also used to demolish concrete and structural elements of a building at the end of its life cycle. Demolition automation provides safety and efficiency, substantial cost savings for construction companies. Demolition robots, although they operate more slowly than demolition crews, are much safer and cheaper.

The use of robots for wall plastering, polishing and painting works is also carried out [6-8].

Plastering is one of the final steps in finishing an interior or exterior wall. Plastering works are distinguished by complex technology and the use of a large number of manual working methods. Their implementation is associated with increased humidity, spraying the plaster mixture, vibration, which makes this type of work harmful to health $[9,10]$. At the same time, homeowners demand higher quality plastered surfaces. This is due to higher housing standards, the quality of materials of the final interior decoration. There are also special requirements for perpendicularity, deviation from the plane and irregularities. When plastering agricultural premises, it is also necessary to ensure high quality and productivity.

When using automation, the amount of manual labor will decrease, labor productivity will increase significantly, and the quality of plastering work will improve [10,11]. Unlike the manual process, automation allows us to plaster quickly and evenly, improve surface quality, save plaster mixture [8].

When performing plastering works, it is important to ensure the fulfillment of two conditions: the flatness of the wall and the uniform density of the layer of plaster. If the applied layer of plaster does not correspond to the required compaction, this can lead to local dents, cracking, delamination and blistering [6]. However, for the robots used in the construction, a control system is needed [12].

In case of significant irregularities of the plastered surface when applying the plaster, it is necessary to adjust its quantity taking into account these irregularities. This can be done in two ways: by changing the productivity or speed of the nozzle. We will determine the most preferred method and develop technique for realizing the determination of the amount of applied plaster mixture on the plastered wall.

\section{The method of controlling the amount of applied plaster mixture by changing of the nozzle performance}

Consider the first way to adjust the amount of plaster mixture directly by changing the nozzle performance. For this, it is preliminary proposed that the surface to be treated (for example, a rectangular wall) be divided into squares in an amount of $n \cdot m$, where $n$ is the integer number of squares horizontally; $m$ is the integer number of squares vertically. Then the calculation of the required amount of plaster mixture to eliminate unevenness of the entire surface is calculated by the formula:

$$
T=S \cdot \sum_{i=1}^{n} \sum_{j=1}^{m} G_{i j},
$$


where $G_{i, j}$ is the average height of the missing plaster in the $i, j$ square of the wall; $S$ is the area of square.

This method of calculating the flow rate of the plaster mixture and the corresponding change in the speed of the nozzle will reduce the cost of the plaster mixture and improve the surface quality. In this case, the task is reduced to minimizing the following criteria:

$$
\int_{0}^{T}\left(V_{p e r}(t)-V(t)\right)^{2} d t \rightarrow \min ,
$$

where $V_{p e r}(t), V(t)$ are the dependence of required and real volume of plaster mixture on current time; $T$ is the total time for applying the plaster mixture.

However, the disadvantage of this method is the need for a preliminary calculation of the time moment of the nozzle productivity change [13]. The difficulty in solving this problem is associated with inertia resulting from speed limits and accelerated consumption of the plaster mixture from the nozzle, as well as the time required to reach the surface of the plaster mixture.

\section{The method of controlling the amount of plaster applied by changing the speed of the nozzle}

In connection with these difficulties, it is proposed to use the second method of adjusting the amount of plaster mixture by optimizing the speed of the nozzle. It is proposed to apply the plaster mixture by moving the nozzle horizontally with the transition to the next level from bottom to top. The horizontal speed of the nozzle is determined from the expression:

$$
v_{i, j}=a / T_{i, j}
$$

where $T_{i, j}=V_{i, j} / q$ is the time required to fill the irregularities of the $i, j$ square of the wall with plaster mixture of the volume $V_{i, j}$.

As shown by studies, there are two ways to control the amount of plaster applied, however, the method based on changing the speed of the working tool is the most appropriate.

The algorithm for determining the nozzle speed based on measuring the height of the missing layer has the following form.

For each $i, j$ square $(i=1, \ldots, n, j=1, \ldots, m)$ of the wall with an area of $S=a \cdot a$ :

1. To determine the volume of the missing plaster mixture $V_{i, j}=S \cdot G_{i, j}$.

2. To calculate the speed $v_{i, j}$ of the nozzle so that the volume of applied mixture on the $i, j$ square is equal $V_{i, j}$ by the formula $v_{i, j}=a /\left(V_{i, j} / q\right)=q /\left(a \cdot G_{i, j}\right)$.

For simulation of the developed methodology for controlling the amount of applied plaster mixture, it is proposed to use a DC motor to carry out the movement of the nozzle in a horizontal line. DC motor, which is described by a system of the differential equations [14]:

$$
\begin{aligned}
& \left(L \frac{d}{d t}+R\right) \cdot I=y-k_{a} \frac{d x}{d t}, \\
& J \frac{d^{2} x}{d t^{2}}=k_{m} I,
\end{aligned}
$$


where $x$ is angle of rotation of the motor shaft; $y$ is control signal; $I$ is current in the motor armature-circuit; are armature-circuit inductance and resistance of the motor; $J$ is moment of inertia of the engine; $k_{\omega}$ is coefficient of counter-electromotive force; $k_{m}$ is proportionality coefficient, connecting current and the moment developed by the motor.

The simulation was carried out in the Matlab Simulink system $[15,16]$. In the simulation, the following parameters of the DC motor were used: rated torque $M=0.286 \mathrm{~N} \cdot \mathrm{m}$, rated current $I=4.5 \mathrm{~A}$, armature-circuit inductance $L=6.58 \cdot 10^{-4} \mathrm{H}$, armature-circuit resistance $R=0.94 \mathrm{Ohm}$, armature moment of inertia $J=2 \cdot 10^{-5} \mathrm{~kg} \cdot \mathrm{m}^{2}$, electromechanical constant $T_{M}=3.8 \cdot 10^{-3} \mathrm{~s}$, electromagnetic constant $T_{e}=0.7 \cdot 10^{-3} \mathrm{~s}$.

The block diagram of the nozzle movement control system is shown in figure 1. For horizontal movement of the nozzle, a DC motor is used. The control system takes into account the information supplied from the distance sensor of irregularities of the plastered surface, the mathematical model of the DC motor, a gearbox that converts the rotation of the motor shaft into the translational movement of the nozzle.

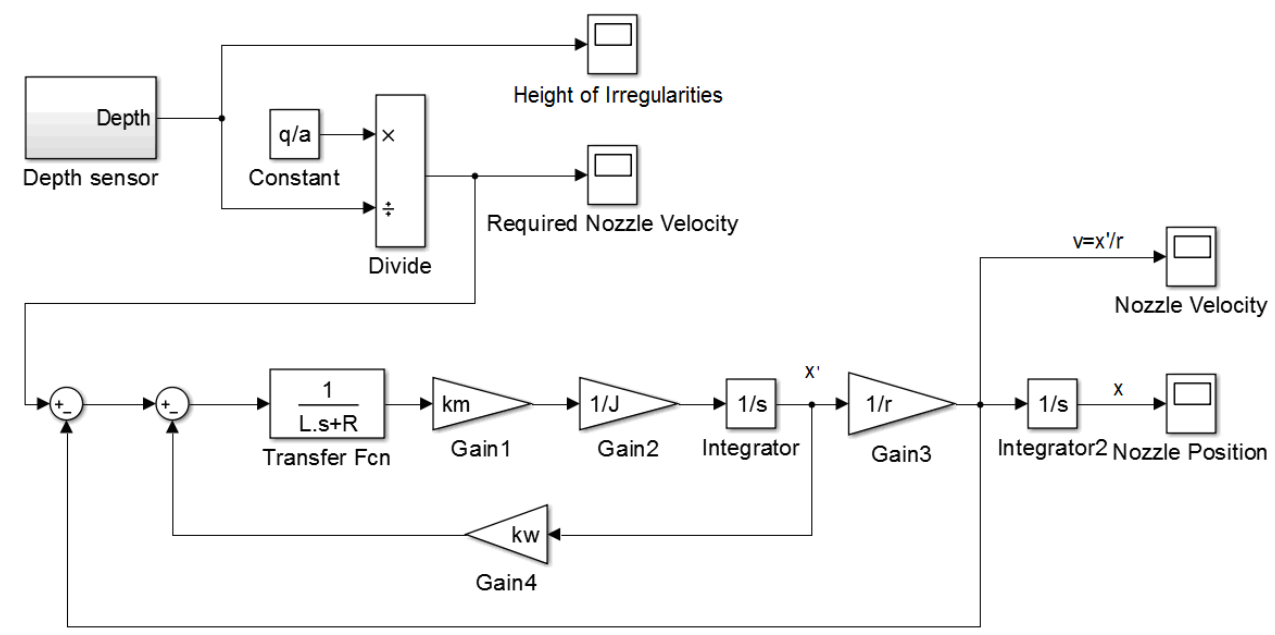

Fig. 1. The block diagram of the nozzle movement control system.

The results of measuring the wall irregularities are shown in figure 2 . The height of irregularities ranges from 0.01 to 0.05 meters. 


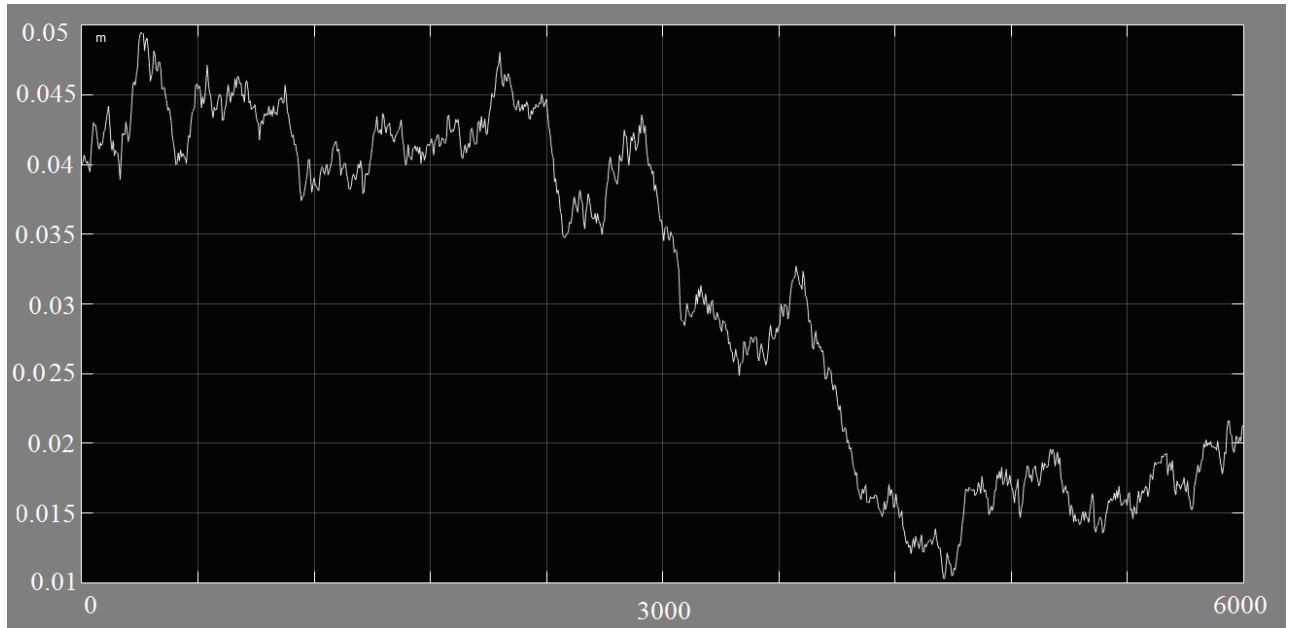

Fig. 2. The dependence of wall irregularities on sector number.

The simulation results of the process of applying plaster to the wall with irregularities are shown in figure 3 and figure 4 . The speed-time and position-time graphs are shown when the nozzle moves when applying the plaster.

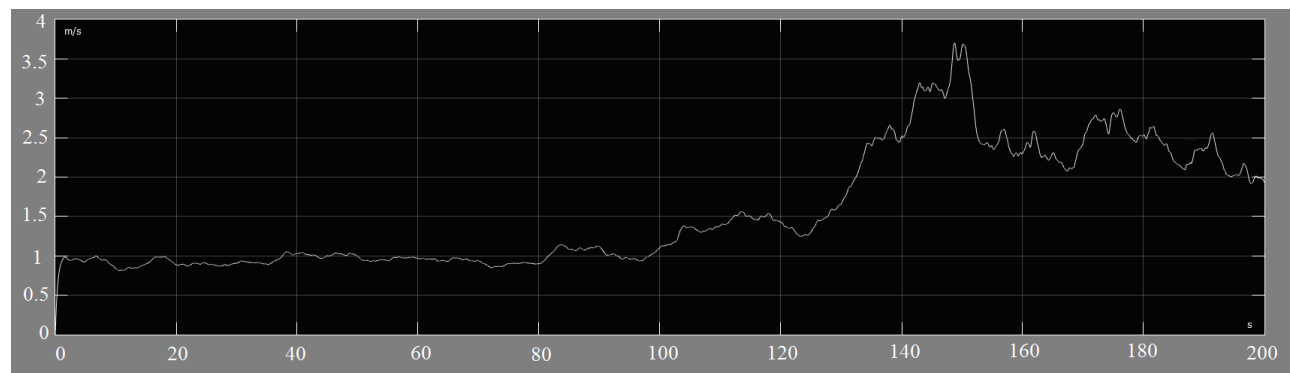

Fig. 3. The speed-time graphs of movement of the nozzle.

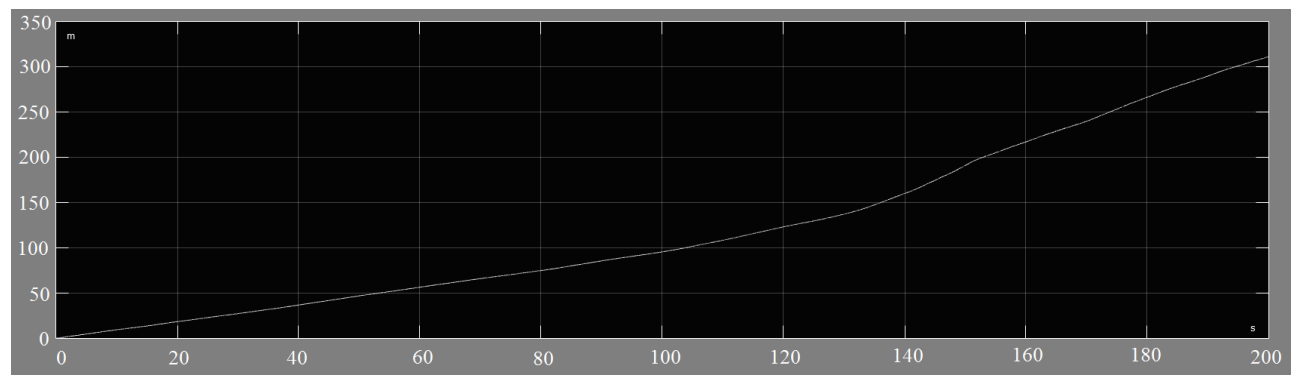

Fig. 4. The position-time graphs of movement of the nozzle.

\section{Conclusions}

The developed technique for applying the plaster mixture with automatic adjustment of the nozzle speed when applying the plaster mixture provides the necessary speed of the working tool depending on the wall irregularities. Using automation of plaster application 
allows to reduce the time of plastering walls, provides high quality plastered walls and provides high economic efficiency.

\section{References}

1. H. Ardiny, S. Witwicki, F. Mondada, International Journal of Robotics Theory and Applications 4(3), 10-21 (2015)

2. S.M. Moon, D. Hong, S.W. Kim, and S. Park, Proc. of the IEEE International Conference on Industrial Technology, 509-514 (2012)

3. S.K. Rajesh Kanna, A.D. Jaisree, International Journal on Recent and Innovation Trends in Computing and Communication 3(9), 5659-5662 (2015)

4. S. Sundara Mahalingam, S. Arockiaraj, V.P. Gowtham Kumar, B.V. Manikandan, Journal of Advanced Research in Dynamical and Control Systems 11(1), 255-260 (2019)

5. Z. Dakhli, Z. Lafhaj, Cogent Engineering 4(1) (2017) doi: 10.1080/23311916.2017.1361600

6. M.T. Sorour, M.A. Abdellatif, A.A. Ramadan, A.A. Abo-Ismail, International Journal of Mechanical Aerospace, Mechatronic and manufacturing Engineering 5(11), 1785$1792(2011)$

7. H. Ji, X. Jiang, Y. Du, P. Shan, P. Li, C. Lyu, W. Yang, and Y. Liu, IEEE International Conference on Real-time Computing and Robotics (RCAR), 677-682 (2017) doi: 10.1109/RCAR.2017.8311942

8. A. Bulgakov, T. Bock, J. Otto, International Multi-Conference on Industrial Engineering and Modern Technologies (FarEastCon), 1-5 (2019) doi: 10.1109/FarEastCon.2019.8934132

9. X. Li, X. Jiang, IEEE International Conference on Mechatronics and Automation (ICMA), 1417-1422 (2018) doi: 10.1109/ICMA.2018.8484421

10. A. Zholobov, N. Ivannikova, O. Razinkova, P. Dukhanin, Innovative Technologies in Environmental Science and Education (ITESE-2019) 135, 03047 (2019) doi: 10.1051/e3sconf/201913503047

11. E. Asadi, B. Li, I. Chen, IEEE Robotics \& Automation Magazine 25(2), 82-94 (2018) doi: 10.1109/MRA.2018.2816972

12. C. Casnudas de Wit, B. Siciliano, G. Bastin, Theory of Robot Control 392 (2012) doi: 10.1007/978-1-4471-1501-4

13. Q. Yel, B. Shen, O. Tiedje, J. Domnick, Journal of Energy and Power Engineering 7, 74-81 (2013)

14. P.M. Meshram, R.G. Kanojiya, IEEE-International Conference on Advances in Engineering, Science and Management (ICAESM), 117-122 (2012)

15. S.T. Karris, Introduction to Simulink: With Engineering Applications (2011)

16. S.L. Eshkabilov, MATLAB ${ }^{\circledR} /$ Simulink ${ }^{\circledR}$ Essentials: MATLAB ${ }^{\circledR} / \operatorname{Simulink}{ }^{\circledR}$ for Engineering Problem Solving and Numerical Analysis (2016) 